\section{O ICM, OS INVENTÁRIOS E O IMPÔSTO DE RENDA Tarcisio Neviani*}

A implantação da reforma tributária, em 1967, implicou em verdadeira comoção. Esta resultou da alteração de critérios legais de tributação e da definição, em diploma legal orgânico (Código Tributário Nacional), das normas gerais de direito tributário que, daí por diante, só poderiam sofrer alterações por lei complementar da Constituição, aprovada por maioria qualificada do Congresso.

Dentre as modificações que mais profundamente abalaram as estruturas tributárias anteriores, alinha-se a da substituição do ineconômico e arcaico impôsto de vendas e consignações, pelo impôsto sôbre circulação de mercadorias; êste essencialmente diferenciado do anterior, por incidir sôbre o valor acrescido às mercadorias em cada uma das operações. Estabeleceu-se um sistema, de dois possíveis, para que cada contribuinte, assim definido na lei, só fôsse responsável pelo impôsto incidente sôbre a porção de valor que o próprio contribuinte agregasse à mercadoria.

A passagem do impôsto sôbre vendas e consignações (que incidia em cascata, sôbre o valor integral de cada operação, sem atentar para o valor da operação anterior) para o de circulação de mercadorias, implicou em sérias preocupações de caráter econômico para o Govêrno. O país atravessava uma fase * Professor do Departamento de Ciências Sociais da Escola Ge Administraç Vargas.

R. Adm. Emp., Rio de Janeiro de acentuada inflação monetária e desenvolvia enormes esforços para reduzir o seu ritmo. Os vendedores (comerciantes e industriais) já estavam acostumados a computar, como custo, o montante do Ivc incidente sôbre os bens vendidos, o que era bastante simples, uma vez que a percentagem conhecida (6,6\% em São Paulo) incidia de forma sêca sôbre o preço de venda, não permitindo qualquer tipo de dedução.

Tendo em vista que o sistema do valor acrescido já era bastante conhecido por ser adotado pelo impôsto de consumo, a mais simples das maneiras seria exigir nas notas fiscais uma parcela em destaque: a do ICM. Tal como o IPI. Exemplificando:

Valor das mercadorias (preço comercial independente do impôsto) 100

ICM p. ex. $17 \%$

IPI p. ex. $12 \%$

Total da nota fiscal $\quad 129$

Entretanto, os vendedores não mais passariam a dever o IVc, cujo valor previsto já integrava a base de 100, no momento da implantação do IcM. Permitir o mero acréscimo aos preços vigentes do montante do ICM significaria dar aos vendedores a oportunidade de se locupletarem. De fato, se no tempo do Ivc, tivessem uma receita líquida de

$11(2): 33-40$

Abr./Jun. 1971 
$100-6,6=93,4$, a vigorar o ICM por fora da base de cálculo, êles poderiam auferir, de pronto, uma receita líquida de 100 . O locuple.. tamento corresponderia, pois, ao valor do IVC já incluído por êles ao formarem os seus preços, e que deixaria de ser devido. As consequências econômicas seriam desde logo desastrosas: generalizar-se-ia um aumento de dispêndio pelos compradores equivalente à alíquota do ICM (15\%). Isto equivaleria a uma desvalorização monetária abrupta e, portanto, inutilizaria quase completamente os esforços antiinflacionários.

Face à urgência da implantação da reforma tributária como integrante dos planos de reestruturação da vida econômica nacional, o Govêrno desprezou as demais alternativas, para promulgar o Ato Complementar n. 27 , de 1966 , cujo artigo $1 .^{\circ}$ originou o $\$ 4 .^{\circ}$ do artigo 53 do Código Tributário Nacional declarando incluso no preço das mercadorias o montante do ICM devido. Dessa forma, evitou-se o inconveniente apontado no parágrafo acima, uma vez que os vendedores não mais poderiam tentar atribuir ao ICM qualquer aumento de preços, que deveria ser justificado em face da legislação em vigor na época, para incentivar a contenção dos preços.

Parece claro que a providência legislativa apontada não impediu a ocorrência de aumentos nos preços. Entretanto, não permitiu a especulação dos interessados em tôrno da superveniência do ICM, que seria fàcilmente erigido à condição de bode expiatório.

A não serem os motivos apontados, não se encontra explicação para a alteração do conceito da base de cálculo do ICM operado pelo artigo $1 .^{\circ}$ do Ato Complementar n.o 27. O destaque e a soma na nota fiscal da parcela do ICM, à guisa do que ocorre com o IPI, constituiriam técnica muito mais simples, imediata e não causariam tantos equívocos por parte de contadores, formadores de preços e intérpretes da legislação. Além disso, evitariam as inúmeras discussões, por vêzes de desastrosas conseqüências para alguns contribuintes, surgidas do fato de o IPI ser calculado com base em valor que já inclui o montante do ICM. Esse fato, pôsto que seja jurìdicamente irrelevante face à legislação tributária vigente, é, entretanto, econômicamente inegável. Sob certos aspectos, há quem, com algumas razões, considere inconstitucional o referido $\S 4 .^{\circ}$ do artigo 53 , incluído no Código Tributário Nacional pelo artigo $1 .^{\circ}$ do Ato Complementar n. ${ }^{\circ} 27 .{ }^{1}$

O \& 4..$^{\circ}$ do artigo 53 do Código Tributário Nacional foi substituido pelo $\S 7 .^{\circ}$, do artigo 2. ${ }^{\circ}$, do Decreto-lei n. ${ }^{\circ} 406 / 68$, também de constitucionalidade duvidosa, uma vez que inseriu alterações na legislação tributárıa, que só uma lei complementar poderia introauzir. Para a parte que interessa ao presente estudo, o Decreto-lei n. ${ }^{0}$ 406/68 não trouxe qualquer alteração substancial.

Pelos motivos expostos e face ao próprio contexto das leis tributárias, que incluem o princípio de que o ICM faz parte de sua própria base do cálculo, não parece haver razão para afirmar que o legislador tenha visado a conseqüências contábeis tendentes a considerar como custo o ICM nela incorporado. De início, verifica-se que, em nenhum dos textos legais referentes ao ICM, se encontra sequer a palavra custo, no que os legisladores se houveram bem, pois evitaram utilizar um têrmo econômico ou contábil tão vago, abrangente e compreensivo como êsse é. Não deve o intérprete da lei incorrer no êrro que o legislador evitou. Confundir base de cálculo de qualquer tributo com custo de alguma coisa é mal-entender a lei e se desentender com a economia e com a contabilidade. Por essas razões, substituir o conceito custo pelo conceito base de cálculo é estender o alcance da lei tributária, o que contraria regras de interpretação consagradas na doutrina. Além disso, a legislação do ICM não se importa com custo algum; importa-se apenas com a base de cálculo, que nem sempre coincide com o preço pago na operação, que continua a ser base de cálculo mesmo nas operações de valor

1 Aralida, GeraIdo, Sistema constitucional tributário brasileiro, São Paulo, 1968. p. 258-9. 
não determinado (transferências, doações etc.) e que não implicam em custo. ${ }^{2}$ Só por isso, a identificação ou, o que é pior, a troca dos conceitos é insustentável.

De outro lado, o dispositivo legal citado ensejou êrro ainda maior: além de se confundir base de cálculo do ICM com custo de mercadorias, confunde-se amiúde o próprio custo com simples desembôlso temporário de dinheiro. quase curial que se uma parcela do preço pago, das mercadorias, é de alguma forma recuperável, não constitui custo, mas apenas desembôlso. Tal se afigura a parcela do ICM integrando a sua própria base de cálculo: desde que enseje crédito fiscal para o comprador que vai revender, essa verba não será custo, apenas desembôlso.

A colocação dos precedentes conceitos elementares é útil e básica para a solução dos problemas de formação de preços na parte que diz respeito ao ICM. Apesar de idêntico em sua mecânica, o IPI não oferece dificuldades para a formação dos preços, simplesmente porque não está incluído em sua própria base de cálculo e não cria confusões.

Quando um comerciante, industrial ou produtor acaba de apurar o seu custo unitário total (matérias-primas, mão-de-obra, depreciações, despesas indiretas, despesas gerais), defronta-se com o problema de conhecer a que preço deverá vender o produto para obter um lucro predeterminado, por êle desejado e tributável pelo impôsto de renda. No que tange ao presente estudo, o problema é o mesmo para o fisco, quando fiscaliza os métodos contábeis do contribuinte para averiguar a exatidão do lucro oferecido à tributação.

1. Suponha-se que um contribuinte do ICM deseje um lucro unitário de $\mathrm{Cr} \$ 100,00$ e que o desembôlso unitário total esteja assim estruturado:

2 cTN, Art. 47, II, b; 53, II; Decreto-le1 $406 / 68$, art, $2 .^{\circ}$, incisos II e IIr; Decreto estadual (SP) n. ${ }^{\circ}$ 51.345, art. 8. Incisos II e III.

Abril/Junho 1971

$$
\begin{aligned}
& \text { Matérias-primas (valor desem- } \\
& \text { bolsado na aquisição) } \quad 100,00 \\
& \text { Mão-de-obra e outros compo- } \\
& \text { nentes } \\
& 225,00 \\
& 325,00
\end{aligned}
$$

Face ao dispositivo legal já mencionado, que manda incluir o ICM em sua própria base de cálculo e considerando uma alíquota de ICM de $15 \%$ (para simplificar as contas), depreende-se que o valor de aquisição das matérias-primas compõe-se conforme segue:

$$
\begin{array}{lr}
\text { Custo real das matérias-primas } & 85,00 \\
\text { ICM a recuperar } & 15,00 \\
\hline & 100,00
\end{array}
$$

Suponha-se o seguinte: a) o contribuinte possuía no início do período (inventário inicial) matéria-prima suficiente para fabricar 10 unidades; b) adquiriu mais durante o período, pelo mesmo preço, para produzir outras 30 unidades e c) vendeu ao todo 15 unidades. Qual será o preço unitário a praticar para realizar o lucro efetivo de $\mathrm{Cr} \$ 100,00$ por unidade? Pôsto que praticado êsse preço, como tratar a parcela de ICM incluída no valor de compra das matérias-primas, para que se ofereça ao Impôsto de Renda o lucro unitário real de vendas de $\operatorname{Cr} \$ 100,00$ ?

1.1 A primeira das questões propostas, não fôra o ICM incluído no seu valor tributável, a resposta seria imediata e elementar: custo, mais lucro desejado, igual a preço de oferta. Portanto, seria Cr $\$ 425,00$. Entretanto basta lembrar que os Cr\$425,00 devem incluir o valor do ICM a ser pago pelo contribuinte no momento das vendas (Cr\$ 63,75, no caso), para perceber que:

Receita de Vendas

425,00

- Desembôlso total

325,00

100,00 
- ICM a pagar e destacado na nota fiscal

63,75

36,25

+ ICM a recuperar (sôbre matéria-prima)

15,00

Lucro bruto

51,25

Uma tal desatenção causaria prejuízo virtual ao contribuinte que veria o seu lucro reduzido de Cr\$100,00 para Cr\$51,25, depois de cumpridas as obrigações fiscais relativas ao ICM. Não é êsse o preço procurado.

1.2 Considerando-se que o valor composto pela soma dos custos, mais lucros desejados $(\mathrm{Cr} \$ 425,00)$ deve ser acrescido de montante suficiente a cobrir o pagamento devido ao fisco estadual e que êsse mesmo montante constitui parte da sua própria base de cálculo, poder-se-ia admitir como preço de oferta o resultante da seguinte proporção simples:

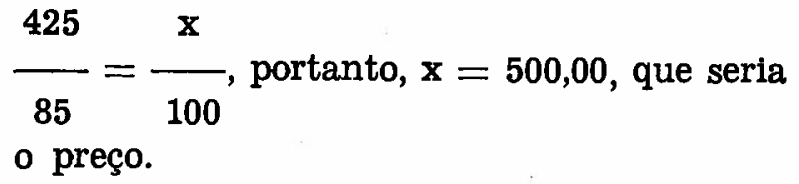

Efetuando-se o mesmo teste anterior, verificar-se-á que:

Receita de vendas

500,00

- Desembôlso total 325,00

- ICM a pagar (destacado na nota fiscal)

175,00$$
\text { nota fiscal) }
$$

+ ICM a recuperar (sôbre matéria-prima)

Lucro bruto

$\frac{15,00}{115,00}$

Neste caso, evidencia-se outro êrro: o lucro realizado seria superior ao desejado e, sem nenhuma coincidência, a diferença é justamente o valor do ICM incluído no valor das matérias-primas e considerado (por deliberado êrro) como custo.
1.3 Reduza-se o valor do desembôlso pelas matérias-primas ao seu custo real, retirando-se-lhe a parcela do ICM sôbre elas incidentes e os números apresentar-se-ão assim:

Custo das matérias-primas

$$
\begin{array}{lr}
(100-15) & 85,00 \\
\text { Outros custos } & 225,00 \\
\hline & 310,00
\end{array}
$$

portanto, para realizar o lucro desejado de Cr\$ 100,00 por unidade, temos:

$$
\frac{410}{85}=\frac{x}{100}, \text { donde } x=482,35 \text {. }
$$

Com o mesmo critério anterior, verifica-se:

Receita de venda (base de cálculo do ICM na venda) 482,35

- Custo real das matérias-primas

$$
\text { - Outros custos }
$$

- ICM a pagar (destacado na nota fiscal)

72,35

Lucro bruto

1.4 Verifica-se, pois, após ensaios e erros deliberados, que o único modo de formar preço de oferta suficiente para obter o lucro desejado é considerar o ICM incidente sôbre as matérias-primas como não integrado no custo destas. No exemplo do item 1.1, há dois erros: a) inclusão do ICM como custo das matérias-primas e b) desconsideração da inclusão do ICM em sua própria base de cálculo; no exemplo do item 1.2 foi sanado o êrro (b) e mantido o êrro (a). Por fim, no item 1.3, ambos os erros foram eliminados e obtido o resultado correto. Este representa o lucro real do contribuinte, sujeito à tributação pelo impôsto de renda. O problema foi colocado com o pressuposto de que o contribuinte não teria limites externos à formação do seu preço, mas serviu para provar que basta in- 
cluir no custo das matérias-primas (estoques dos comerciantes) o valor do ICM sôbre elas incidente para se determinar uma distorção do lucro obtido.

1.5 O raciocínio aqui apresentado poderá sofrer a observação de que partiu de um custo e de um lucro conhecido para chegar a um preço de oferta e que, na prática, em relação ao impôsto de renda, o procedimento é inverso: dos preços praticados, menos os custos, chega-se ao lucro, que é a incógnita procurada. A observação em nada infirma 0 que foi dito, como se pode perceber nos itens que se seguem.

2. Verifica-se que em função dos desembolsos dados, da alíquota do ICM dada e do lucro desejado, o contribuinte deve praticar o preço unitário de $\mathrm{Cr} \$ 482,35$. Tentemos agora responder à segunda questão formulada no item 1.1. Face ao exposto, as reflexões do item 1.4 antecipam a resposta, mas esta pode ser testada de outra forma:

2.1 O contribuinte em questão operou, durante o seu exercício, do seguinte modo:

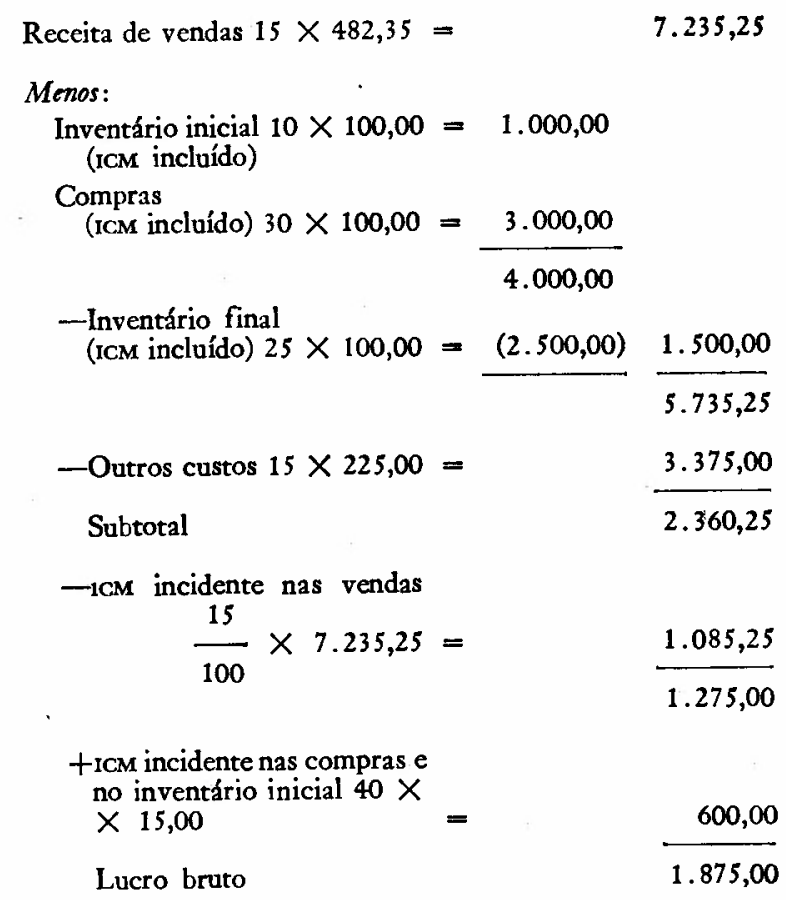

Verifica-se que a inclusão no custo dos inventários do ICM incidente nas compras de matérias-primas implica em aumentar fictìciamente o lucro (que deveria ser $1.500=$ $=15 \times 100$ e resulta em $1.875,00)$. Observa-se que excluir da receita de vendas o total do rCM nelas incidente e depois aumentar essa mesma receita com o valor do ICM recuperado, equivale a deduzir da mesma receita de vendas tão-sòmente o valor do ICM efetivamente recolhido ao erário, após a compensação dos créditos provenientes das compras.

2.2 Considere-se agora a exclusão do ICM do valor do inventário final, apenas. Tem-se:

$$
\begin{aligned}
& \text { Receita de vendas } 15 \times 482,35=\quad 7.235,25 \\
& \text { Menos: } \\
& \text { Inventário ini- } \\
& \text { (ICM incluído) } 10 \times 100,00=1.000,00 \\
& \text { Compras (ICM } \\
& \text { incluído) } \\
& 30 \times 100,00=\frac{3.000,00}{4.000,00} \\
& \text {-Inventário } \\
& \text { final } \\
& \text { (ICM excluí- } \\
& \text { do) } 25 \times 85,00=\underline{(2.125,00)} \frac{1.875,00}{5.360,25} \\
& \text {-Outros cus- } \\
& \text { tos } 15 \times 225,00=\frac{3.375,00}{1.985,25} \\
& \rightarrow \mathrm{ICM} \text { incidente nas vendas } \\
& \frac{15}{100} \times 7.235,25=\frac{1.085,25}{900,00} \\
& \text { +rCM incidente } \\
& \text { nas compras } \\
& \text { inicial } 40 \times 15,00= \\
& \text { Lucro bruto } \\
& \frac{600,00}{1.500,00}
\end{aligned}
$$

Resulta um lucro adequado, correto, à razão de $C r \$ 100,00$ por unidade vendida, uma vez que se reinclua o valor do ICM incidente nas compras e no inventário inicial, que fôra mantido como custo. Equivale, pois, a excluir o mesmo ICM do valor de todos os inventários. Se se atender ao jôgo de créditos 
e débitos do ICM, verifica-se que o saldo devedor recolhido pelo contribuinte terá sido:

$$
\begin{array}{lr}
\text { débitos de ICM (vendas) } & 1.085,25 \\
\text { créditos de ICM } & 600,00 \\
\hline & 485,26
\end{array}
$$

valor êsse que, deduzido do subtotal $1.985,25$, resulta no lucro bruto de $\mathrm{Cr} \$ 1.500,00$ que, no caso, é o correto. Isto explica e justifica uma provisão para impostos a pagar quando o recolhimento deve ocorrer no exercício seguinte.

2.3 Pode-se chegar ao mesmo resultado, excluindo-se o ICM de todos os valôres dos inventários contanto que se deduza do subtotal resultante o montante integral do ICM debitado nas notas fiscais de venda:

$$
\begin{aligned}
& \text { Receita de vendas } 15 \times 482,35= \\
& 7.235 .25 \\
& \text { Menos: } \\
& \text { Inventário ini- } \\
& \text { cial } \quad 10 \times 85,00=850,00 \\
& \text { Compras } \quad 30 \times 85,00=2.550,00 \\
& \text {-Inventário fi- } \\
& \text { nal } 25 \times 85,00=\underline{(2.125,00)} \frac{1.275,00}{5.960,25} \\
& \text {-Outros cus- } 15 \times 225,00= \\
& \text {-ICM incidente nas vendas } \\
& \text { Lucro } \\
& \frac{1.085,25}{1.500,00}
\end{aligned}
$$

Este sistema, embora chegue ao mesmo resultado, oferece uma vantagem em relação ao anterior.

2.4 Essa vantagem manifesta-se no caso em que haja saldos credores do ICM nos livros respectivos ao final do exercício e consiste em não distorcer os resultados, mesmo que se levem em conta êsses saldos credores. Vale a pena demonstrar. Suponha-se agora que o contribuinte tenha vendido apenas cinco unidades, resultando, face ao exposto, num lucro de $\mathrm{Cr} \$ 500,00$ :

$$
\begin{aligned}
& \text { Receita de vendas } 5 \times 482,35= \\
& 2.411,75 \\
& \frac{15}{100} \times 2.411,75=\quad-\frac{361,75}{500,00}
\end{aligned}
$$

Nota-se que houve crédito de ICM nas compras e no inventário inicial de $\mathrm{Cr} \$ 600,00$ e um débito de apenas $\operatorname{Cr} \$ 361,75$, sobrando um saldo credor (para o exercício seguinte) de Cr\$ 238,25.

2.5 Adotando-se a forma do item 2.2, teríamos o seguinte:

$$
\begin{aligned}
& \text { Receita de vendas } 5 \times 482,35]= \\
& 2.411,75 \\
& \text { Menos: } \\
& \begin{array}{r}
600,00 \\
500,00
\end{array}
\end{aligned}
$$

Nesta hipótese, que também chega a resultado correto, houve saldo credor de ICM, que deve ser acrescido ao subtotal para se encontrar o lucro real. 
2.6 preferível, pois, a forma de cálculo apresentada nos itens 2.3 e 2.4 , em vista de sua coerência e simplicidade maior.

Com os exemplos dos itens anteriores ficou demonstrada a procedência da orientação das autoridades do impôsto de renda nas decisões dos processos n. ${ }^{\text {s }}$ 122.584/68 (Indústria de Papel Simão s.A.), 90.272/68 (Indústria de Móveis Francisco Bergamo Sobrinho S.A.), 162.040/68 (Dufer s.A.), onde diz:

"O destaque (do IPI e do ICM), a meu ver, deverá ser completo, isto é, serem referidos impostos excluídos do inventário de abertura e das compras e vendas, valendo isso dizer que o será também do inventário final, funcionando assim o esquema durante todo o exercício. E evidente que o destaque terá de ser rigorosamente coincidente com o crédito fiscal que a pessoa jurídica tiver a recuperar por (via de) compensação nos pagamentos a serem feitos futuramente ao Estado" (parênteses acrescentados; grifos do original).

No presente estudo foram usados exemplos numéricos por serem de apreensão mais imediata e sintética. Dêles pode-se concluir que:

Se na data do balanço o saldo do ICM fôr devedor, não haverá distorção no lucro tributável desde que:

a) se exclua o ICM apenas do valor desembolsado correspondente aos inventários finais;

b) se deduza da receita de vendas a totalidade dos saldos devedores apurados nos livros fiscais até a data do balanço; a dedução se dará ou como despesa (se o tributo já foi recolhido), ou como provisão de impôsto, a pagar no exercício seguinte, mas já devido.

Seja devedor ou credor o saldo de ICM nos livros fiscais, na data do balanço, não haverá distorção no lucro tributável desde que:

a) se exclua o ICM de todos os valôres correspondentes às compras e aos inventários (inicial e final); b) se deduza da receita de vendas a totalidade do ICM debitado nas notas fiscais emitidas durante o exercício. A parte ainda não recolhida poderá ser objeto de provisão. $O$ restante, como despesa.

Se o saldo de ICM fôr credor na data do balanço, não haverá distorção no lucro tributável desde que:

a) se exclua o ICM apenas dos valôres relativos ao inventário final;

b) se acresça à receita de vendas o valor do saldo credor em questão.

Parece inadequada qualquer orientação no que diz respeito ao tratamento do ICM incidente na aquisição das mercadorias componentes dos inventários, que não se enquadre em uma das modalidades acima. Traídos pelo exame do texto legal mencionado (inclusão do ICM em sua própria base de cálculo) muitos e respeitáveis intérpretes da lei resvavalaram em êrro, ou, pelo menos, em falta de clareza, porque não se voltaram para a aplicação prática dos princípios que lhes pareceram corretos. $\mathrm{Em}$ verdade, o direito se insere no contexto do conhecimento humano e não dispensa os demais ramos do saber quando se trata de entender as coisas. $O$ teste numérico em tais casos é decisivo e suficiente para evidenciar que nem sempre a mera interpretação jurídica dos textos legais, como aparentam ser, é suficiente. Alegou-se que, se o ICM é, por fôrça de lei, parte integrante de sua própria base de cálculo, êle constitui elemento do custo real da mercadoria, cuja circulação tributa. Daí inferiu-se que ao custo de aquisição dos produtos inventariados há que agregar-se o montante do ICM que lhes onerou a aquisição. Caso contrário, os livros de inventário acusariam quantia menor do que o custo real. Como se viu, o problema é apenas aparentemente jurídico e várias são as formas possíveis e aceitáveis de se tratar o ICM incidente na aquisição de estoques. Não é problema jurídico, pois o critério legal para 
determinar a base de cálculo do ICM é objeto de disposição legal específica, não geral, nem genérica. Aplica-se, pois, para os estritos fins e efeitos de cálculo do ICM e aí se esgota. Caso o legislador efetivamente pretendesse dilatar-lhe os efeitos, di-lo-ia explìcitamente e inseriria norma análoga ou remissiva na legislação específica do impôsto de renda. Concluir o contrário só é tolerável como argumento heróico de defesa de uma situação consumada, mas não constitui jurídica orientação.

Ademais, desde a Lei n. ${ }^{\circ} 154 / 47$, cujos dispositivos aplicáveis ao assunto estão consolidados no artigo $225, a \cdot \mathrm{e} b, \S \S 2 .^{\circ}$ e $4 .^{\circ}$ do atual regulamento do impôsto de renda (Decreto n. ${ }^{\circ}$ 58.400/66), a legislação brasileira se fixou, univocamente, em adotar, para valor de inventário, o seu custo real. Vale lembrar o que dispõem os parágrafos $3 .^{\circ}$ e $4 .^{\circ}$ :

"§ 3.0 No caso das indústrias, os produtos em fabricação deverão constar do livro de inventário pelo seu preço de custo, ficando também em separado e pelo seu preço de custo, as matérias-primas sem qualquer beneficiamento".

“§ 4.0 O valor das mercadorias ou produtos deverá figurar no livro de inventário pelo custo de aquisição ou de fabricação, ou pelo preço corrente no mercado ou Bôlsa, prevalecendo o critério de estimação pelo preço corrente, quando êste fôr inferior ao preço de custo".

Por sua vez, a Lei das Sociedades por Ações contém dispositivos (artigo 129, parágrafo único) correspondente, adotando o critério do custo ou do valor de mercado (qual seja o menor), para matérias-primas, produtos acabados e, compreensìvelmente, produtos em curso de fabricação.

No tocante à apuração do lucro tributável e aos demais efeitos relativos ao impôsto dé renda, prevalecem as disposições do mencionado regulamento, e delas se depreende o seguinte:
O balanço comercial deve ter as matériasprimas avaliadas pelo custo ou pelo valor de mercado qual seja o menor; o mesmo ocorrerá com os produtos, acabados ou não, destinados à venda.

O balanço fiscal terá as matérias-primas e os produtos em curso de fabricação avaliados exclusivamente pelo custo real (não desembôlso); as mercadorias e produtos acabados, destinados à venda serão avaliados pelo custo real ou pelo valor de mercado, qual seja o menor.

Ante a distinção conceitual entre custo real e desembôlso bem como perante as normas reproduzidas acima (Decreto n. ${ }^{\circ} 58.400$ / 66), verifica-se que o critério mais adequado, dentre os propostos neste estudo, é o constante do item 2.3, confirmado no item 2.4 (contrario sensu no item 2.5), onde o valor do ICM é excluído de todos os inventários e das compras e vendas, desde que observadas as recomendações a respeito apresentadas neste trabalho. Entretanto, vale lembrar que os outros critérios apontados (exceto o do item 2.1), embora menos adequados, levam ao mesmo resultado se observadas as recomendações pertinentes.

Em conclusão, ficou evidente que sempre constituirá inflação de lucros a manutenção do ICM no valor dos inventários finais. Isto, além de acarretar uma indevida tributação pelo impôsto de renda, pode acarretar uma indevida distribuição de dividendos ou, pelo menos, uma irreal sensação de rentabilidade e, o que é pior, pode favorecer a descapitalização da emprêsa. Estes últimos aspectos devem merecer a especial atenção dos analistas das ações transacionadas nas Bôlsas de Valôres.

A contabilização, em função de qualquer dos critérios apontados neste estudo, não apresenta maiores dificuldades para os profissionais, desde que aceitos os princípios aqui expostos.

Revista de Administração de Emprêsas 